\title{
Autoetnografía: el teatro como herramienta terapéutica para nińos y nińas de una Escuela Hospitalaria
}

\author{
Miriam Maribel Vargas Rivas ${ }^{\mathrm{a}}$, Daniela Olivares Aising ${ }^{\mathrm{b}}$, Roberto Fernández Droguett ${ }^{\mathrm{c}}$ \\ ${ }^{a}$ Universidad Austral de Chile, Valdivia, Chile. \\ ${ }^{b}$ Facultad de Medicina, Universidad Austral de Chile, Valdivia, Chile.

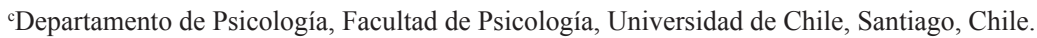

\begin{abstract}
Resumen: Introducción: Este artículo versa sobre la experiencia de un taller de teatro realizado durante el año 2011 en una Escuela Hospitalaria, para niños y niñas con diversas condiciones de salud. El trabajo se convirtió en una posibilidad de difusión del arte como herramienta terapéutica y una invitación para reflexionar sobre la discapacidad y sus limitaciones reales y/o construidas simbólicamente. La problemática central se focalizó en la identificación de presencia de Factores de Riesgo Ocupacional y Apartheid Ocupacional, en el desempeño escolar de niños y niñas de la escuela Hospitalaria y de la autora. Se plantea que algunos de estos, eran provocados por elementos ambientales como también por construcciones simbólico-sociales generadas en torno a la idea de discapacidad. Objetivo: Describir el impacto que genera el uso de un taller de teatro como medio terapéutico en una escuela hospitalaria. Método: La metodología idónea fue autoetnográfica, que valida la experiencia de la investigadora como fuente de información. Desarrollo: Se analizan teóricamente las ideas sobre los Factores de Riesgo Ocupacional y Apartheid Ocupacional, además de los conceptos desarrollados a través del taller y utilizados para el combate de las condiciones adversas. Conclusion: Es necesario que todos experimentemos en nuestros diferentes contextos espacios de "no evaluación" y libertad para el uso, disfrute y despliegue de todas nuestras habilidades. Tener certeza que el cuerpo guarda las vivencias lo que potenciará esa alma resiliente que todos merecemos tener y abrirá camino a la posibilidad de destruir nuestras condiciones determinantes.
\end{abstract}

Palabras claves: Arte, Servicio de Educación en Hospital, Terapéuticas, Antropología Cultural.

\section{Autoetnografia: o teatro como ferramenta terapêutica para crianças da Escola do Hospital}

Resumo: Introdução: Este artigo versa sobre a experiência de uma oficina de teatro realizada durante o ano de 2011, em um Hospital Escola, para crianças em diferentes condições de saúde. O trabalho converteu-se numa possibilidade de difusão da arte como ferramenta terapêutica e um convite para refletir sobre as pessoas em situação de deficiência e suas limitações reais e/ou construídas simbolicamente. A problemática central focaliza a identificação de Fatores de Risco Ocupacional e o Apartheid Ocupacional no desempenho escolar de crianças em um Hospital Escola e da autora. Observaram-se problemas provocados por elementos ambientais e também por construções simbólico-sociais geradas em torno da ideia de "deficientes". Objetivo: Descrever o impacto de uma oficina de teatro como meio terapêutico, em um Hospital Escola. Método: A metodologia aplicada foi a autoetnografia, que valida a experiência da pesquisadora como fonte de informação. Resultados: Analisaram-se teoricamente as ideias sobre os Fatores de Risco Ocupacional e o Apartheid Ocupacional, além dos conceitos desenvolvidos através da

Autor para la correspondencia: Miriam Maribel Vargas Rivas, Escuela de Terapia Ocupacional, Universidad Austral de Chile, Independencia 641, Valdivia, Chile, e-mail: maribelvargasrivas@gmail.com 
oficina e utilizados para o combate das condições adversas. Conclusão: É necessário que experimentemos, em nossos diferentes contextos, espaços que propiciem o "não avaliar" e a liberdade para o uso, o prazer e a manifestação de todas as nossas habilidades. Ter a certeza de que o corpo guarda as vivências que potenciarão a alma resiliente, que todos merecemos ter, e de que tais vivências abrirão caminho para a possibilidade de destruir nossas condições determinantes.

Palavras-chave: Arte, Serviço Hospitalar de Educação, Terapêutica, Antropologia Cultural.

\title{
Autoethnography: theater as a therapeutic tool for Hospital School children
}

\begin{abstract}
Introduction: This article recounts the experience of a theater workshop conducted in a hospital school with children under diverse health conditions in 2011 . The work became a possibility of art diffusion as a therapeutic tool and an invitation to reflect on disability and its real and/or symbolically constructed limitations. The central problem focused on identifying the presence of Occupational Risk Factors and Occupational Apartheid in the school achievement of the hospital school children and the author. Problems caused by environmental elements as well as by symbolic-social constructions generated by the idea of disability were observed. Objective: To describe the impact generated by a theater workshop as a therapeutic means in a children's hospital school environment. Method: The autoethnographic methodology was chosen to validate the experience of the investigator as a source of information. Results: The ideas on Occupational Risk Factors, Occupational Apartheid, as well as the concepts developed in the workshop and those used to combat adverse conditions were theoretically analyzed. Conclusion: It is necessary that we experiment contexts that enable spaces free of evaluation and the freedom to use, enjoy and express all our abilities. We must be certain that the body keeps track of past experiences that potentialize the resilience of the soul, which we all deserve to have and which opens the path to the possibility of destroying our predetermined conditions.
\end{abstract}

Keywords: Art, Hospital Education Department, Therapeutics, Anthropology, Cultural.

\section{Introducción}

Este artículo es el resultado del Seminario de título que realicé en el año 2013 para optar al grado de Licenciada en Ciencias de la Ocupación y Terapeuta Ocupacional de la Universidad Austral de Chile, siendo orientada en el área teórica por la profesora Daniela Olivares, quien figura como segunda autora de este artículo y en el área metodológica por el profesor Roberto Fernández, tercer autor de este artículo. Por lo tanto todo el texto escrito en primera persona refleja el trabajo que realicé siendo aún estudiante de Terapia Ocupacional.

La investigación corresponde a una autoetnografía, ya que busca analizar mis propias vivencias como investigadora y autora principal del documento, basándome en las experiencias de un taller de teatro que realicé durante el año 2011 en una escuela hospitalaria, con el financiamiento de FONDART ${ }^{1}$. Durante ese periodo, este fondo, promovía la inclusión y participación en espacios artístico-culturales a personas que no tuvieran acceso a ellos, por diversas condiciones (sociales, salud, económicas, etc.). En la actualidad esta área ya no es abordada por esas iniciativas gubernamentales.
El trabajo práctico se focalizó en una escuela hospitalaria, que funciona dentro de un recinto médico, que entrega educación preescolar y básica a niños y niñas con diversas condiciones de salud, por lo cual, no pueden asistir a escuelas regulares. Dentro de estas condiciones de salud se destacan diagnósticos oncológicos, discapacidad motora (Mielomeningocele, Parálisis cerebral, Traumatismo encéfalo craneano), trastornos de la comunicación, retraso mental, síndromes genéticos, entre otros. Presentando dificultades para desplazarse, moverse y/o comunicarse además de las múltiples consecuencias derivadas de los tratamientos y/o procesos de intervención médica asociados a ellas² ${ }^{2}$. Estas escuelas propician espacios que posibiliten a los niños y niñas recibir atención educativa correspondiente a su nivel escolar, en el marco de la normativa vigente ${ }^{3}$ y del proceso de Reforma Educativa ${ }^{4}$ de Chile.

La creación de un taller de teatro, al interior del hospital, no sólo se convertía, para mí, en una posibilidad de trabajo de difusión del arte como herramienta terapéutica sino que también como ejecutora de las actividades, resultaba ser una invitación personal para habitar y reflexionar sobre el mundo de la discapacidad y sus limitaciones reales y/o construidas simbólicamente. 
La problemática central de este trabajo se focaliza en identificar Factores de riesgo Ocupacional (WILCOCK, 1998) y Apartheid Ocupacional (KRONENBERG; POLLARD, 2007), en el desempeño escolar de niños y niñas de la escuela Hospitalaria y el efecto que esos factores tendrían también en mi propio desempeño ocupacional como monitora del taller de teatro.

La hipótesis inicial, plantea que algunos de estos factores son provocados por las construcciones simbólico-sociales generadas en torno a la idea de niños y niñas con discapacidad o con condiciones de salud "vulnerable" que los predisponen a frecuentes hospitalizaciones, las cuales suponen una ruptura en sus hábitos y su vida cotidiana ${ }^{5}$ (MÉNDEZ et al., 2004).

El objetivo general de este artículo se centra en describir y reflexionar en torno al impacto que genera el teatro en niños y niñas de una Escuela Hospitalaria, siendo entendido el concepto de "impacto" como aquellos cambios significativos que se produjeron a través del tiempo en el cotidiano de todos nosotros como participantes del taller y además identificar y reflexionar sobre la presencia de "Desequilibrio Ocupacional, Deprivación Ocupacional" (WILCOCK, 1998) y Apartheid Ocupacional (KRONENBERG; POLLARD, 2007) en este contexto.

\section{Método}

La metodología idónea para este trabajo fue la investigación autoetnográfica, ya que, inscrita en la tradición disciplinaria de la etnografía, se sustenta en la idea de que yo como investigadora, pertenezco al contexto social a investigar y por lo tanto mis experiencias y reflexiones se encuentran constituidas e influenciadas por las estructuras sociales predominantes, al igual que la todos los demás participantes, por lo cual, en tanto fuente de información, soy capaz de reflexionar e interpretar mis propias experiencias y las de los otros, como cualquier miembro del campo de estudio (FERNÁNDEZ, 2006), Es necesario entonces mantener siempre una observación crítica y analítica de mi participación y mis propios procesos de transformación mientras investigo.

La autoetnografía se inscribe en un amplio movimiento crítico en las ciencias sociales y en las metodologías cualitativas de la investigación postmoderna. Ya que cuestiona los fundamentos positivistas de las ciencias sociales dominantes, entendiéndose así como un método que, en tanto proceso y producto de investigación, habita en el cruce entre investigador e investigado (HOLMAN, 2005).
Esto es lo que me permite como autora observar y reflexionar en torno a mi propia experiencia mientras realizo la investigación, dándose paso al proceso de reflexividad. Esta, es crucial y predominante en la autoetnografía siendo muy oportuna para el análisis de situaciones de desempeño Ocupacional como las descritas anteriormente y que, en este caso me permiten dar cuenta de los Factores de Riesgo Ocupacional y Apartheid Ocupacional a los que también yo me veo sometida al realizar este trabajo.

La autoetnografía puede ser vista como una política democrática radical, que tiene la intención y el compromiso por la creación de espacios de diálogo y debate; que instiga a buscar y desarrollar algunas herramientas que den forma a posibles cambios sociales (HOLMAN, 2005). Esto es algo que no siempre es bien acogido en el campo de la investigación. Una de las críticas que se le hace a esta metodología es la supuesta insistencia en cuestiones excesivamente personalizadas e individualizadas, a la primacía de la emoción y la impronta de la experiencia. Sin embargo, detrás de ese reproche, sale a la luz una cuestión crucial para las ciencias de la salud y de la Ocupación: Ya no nos podemos negar a la utilización de la interpretación personal de los hechos como fuentes de conocimiento. Hace años la investigación cualitativa reconoce que la interpretación personal no puede ser evadida, no podemos pretender dejarla fuera. Todo hecho observado es siempre producto del cruce de mis sensaciones, ideas y acciones con los elementos de un contexto construido y en permanente cambio. Se trabaja aquí con la deslimitación y desmoralización sobre lo que se puede/debe y/o no se puede/debe describir en un texto académico.

Dejamos atrás, de algún modo, el miedo, al posible descontrol, que caracteriza a nuestra cultura científica occidental y que ha sido el eje en la construcción del pensamiento social (ESTEBAN, 2004) y nos abrimos paso al vértigo de concebir el conocimiento como una construcción compleja, emanada desde las infinitas interpretaciones de cada ser humano múltiple, reflexivo y en permanente interacción.

\section{Los factores de Riesgo Ocupacional}

La teórica de Terapia Ocupacional Ann Wilcock (1998) analiza el concepto de salud, adjudicándole un valor más amplio que sólo el de ausencia de enfermedad, refiriendo que existe en nuestra cultura una comprensión "medicalizada" del concepto, reproducida por el público y los usuarios en general 
del sistema, de manera inadvertida. Es así que ella adhiere a las propuestas del concepto de "Bienestar".

Dentro de este desarrollo es importante recalcar que ella nos lleva a asociar nuestras ocupaciones de la vida diaria con ese estado de bienestar, diciendo que una adecuada distribución del tiempo y de nuestras actividades del día a día, serán siempre un factor catalizador de bienestar y satisfacción ("buena salud").

Frente a estas ideas y en este contexto donde comencé a trabajar, es preciso mantenerme alerta a algunas situaciones que popularmente no generan interés, como por ejemplo: ¿¿Nos preocupa si un niño no pudo jugar hoy? Según lo desarrollado por Ann Wilcock (1998), esto debería ser motivo de preocupación tanto como si él no consiguiera comer o dormir ${ }^{6}$ (FERLAND, 2006).

El juego es el medio a través del cual los niños y niñas, descubren el mundo que les rodea y vivencian el placer (FERLAND, 2006). Es Ocupación fundamental en la infancia, estando enraizado en lo más profundo de las tradiciones populares de la cultura, por lo que puede ser considerado un auténtico espejo social (MUÑOZ; SALGADO, 2006 apud LUCERO; TRIVIÑOS, 2010). Por este motivo funciona como un signo central en la detección de circunstancias de Deprivación y Desequilibrio Ocupacionales de niños y niñas en cualquier contexto.

Jugando se les permite a los niños y niñas con características de salud diferentes a las comunes, dar sentido a las situaciones que viven y profundizar en su comprensión, en este caso, no sólo de sus propias circunstancias de vulnerabilidad, sino también de la presencia de excesivos prejuicios que ellos y ellas tienen con sus compañeros y compañeras sobre sus propias capacidades físicas, mentales y/o emocionales.

¿A qué juegan los niños y niñas de la escuela hospitalaria? A lo largo del taller de teatro fui descubriendo que existían dos "Factores de Riesgo Ocupacional" definidos por Wilcock (1998) dentro del contexto y desempeño escolar de los y las estudiantes de esta escuela hospitalaria; a saber "Deprivación Ocupacional” y "Desequilibrio Ocupacional".

El primero de ellos se refiere a "[...] la influencia de un agente o circunstancias externas que mantienen a una persona alejada de la adquisición, uso o disfrute de alguna cosa o situación [...]" (WILCOCK, 1998, p. 145). Es decir que existen condiciones externas que impedían, en este caso, a los y las participantes, desempeñarse en sus ocupaciones esperadas para su etapa evolutiva, a saber; niños de 4 a 12 años que manifiestan deseos de juegos con pelotas, lazos, carreras, saltos, entre otros. Pero que sin embargo, dada su condición de "salud" son los juegos de mesa su única actividad lúdica ofrecida y permitida.

El segundo factor de Riesgo Ocupacional se entiende como una situación constante, donde el compromiso y la participación en las ocupaciones de las personas no consiguen satisfacer sus necesidades físicas, mentales o sociales. En este caso, los niños y niñas se encuentran condicionados a una rutina desequilibrada, donde las ocupaciones que realizan no responden a las necesidades que cada cual posee según su edad cronológica y sus características personales, siendo sometidos y sometidas la mayor parte del tiempo a actividades no escogidas y poco satisfactorias en su jornada escolar, dejando de lado sus propias necesidades.

Algunas de las condiciones adversas que comencé a detectar en esta escuela hospitalaria correspondían a la falta de personal capacitado que ofrezca a los niños y niñas oportunidad de desarrollar actividades motoras y de juego activo, ya que profesoras y asistentes de educación consideran "riesgoso" que los y las estudiantes participen de actividades motoras dado sus problemas de salud, no existiendo en la malla curricular una asignatura de deportes, o un/a profesor/a de educación física. Además tienen una distribución horaria adecuada a niños y niñas de primer ciclo de educación básica (hasta los 7 años) lo cual no corresponde a las etapas evolutivas individuales de los y las estudiantes que año a año participan de esta escuela. Así también la distribución de las herramientas del ambiente físico, donde, en pequeñas salas, los muebles impiden la deambulación libre y autónoma de los niños y niñas que utilizan sillas de ruedas. También se identifica la marcada actitud asistencialista de las funcionarias de la institución que impiden el desarrollo de habilidades para la autonomía de los y las estudiantes y finalmente el propio contexto hospitalario sobrecargado de elementos simbólicos y represores, por ejemplo encontrarse diariamente rodeados de agentes de salud vestidos con delantales blancos, tránsito constante de personas padeciendo alguna enfermedad, permanente sentencia a guardar silencio y estar quietos en algunos sectores del hospital, especialmente cuando se encuentran bajo la atención médica intensiva que requiera su patología. Estas características, que escapan al importante y valioso apoyo que brindan estas instituciones, evidencian la presencia de "Deprivación y Desequilibrio Ocupacionales" en los niños y niñas que asisten a ella. De esta manera el taller de teatro se transforma en un lugar donde poder jugar libremente, sin las restricciones que los adultos y adultas profesionales de la salud imponían. Pero ¿Cómo me atraviesan también a mí estos temores 
y esta necesidad de cuidar de los niños y niñas? Juntos nos fuimos poco a poco permitiendo que este espacio fuera de liberación. Fue el tiempo que nos ayudó a trabajar los miedos que nos producían permitirnos saltar, correr o se arrastrarnos por el piso. Si no podían jugar así en ningún otro momento de su rutina escolar, este espacio hacia posible que surgieran creación y expresión colectiva genuinas.

\section{El Apartheid Ocupacional}

Una definición práctica de Apartheid Ocupacional es la segregación que algunas personas sufren mediante la restricción de su acceso a una participación digna y significativa en las ocupaciones de la vida diaria, escogidas por ellos y ellas. Se encuentra basada en criterios de raza, color, capacidad, procedencia nacional, edad, sexo, orientación sexual, religión, creencias políticas, estatus en la sociedad, u otras características ocasionadas por fuerzas dominantes mayores a las restricciones que ya evidenciamos anteriormente al referirnos a la Deprivación Ocupacional y al Desequilibrio Ocupacional.

El Apartheid Ocupacional se refiere a construcciones político-sociales que condicionan la manera de relacionarnos como seres humanos en esta sociedad. Sus consecuencias serán siempre culturales, políticas, económicas o sociales. Las cuales de manera sistemática y estructurante, ponen en peligro la salud y el bienestar de individuos, comunidades y sociedades (KRONENBERG; POLLARD, 2007) al estructurar los desempeños de cada individuo según categorías impuestas por los órdenes sociales ya descritos. Órdenes establecidas de manera invisible en nuestro cotidiano, validadas y naturalizadas en nuestros propios actos y relaciones personales.

Frente a una definición tan amplia como esta, es difícil evaluar cuando una situación no corresponde a Apartheid Ocupacional, ya que si somos específicos, permanentemente estamos siendo atravesados por estas convenciones sociales y sobre todo en usuarias y usuarios de la Terapia Ocupacional, dadas las características y necesidades que cada uno de ellos y ellas presentan en su participación Ocupacional en nuestra sociedad.

Para este contexto, podemos referirnos a Apartheid Ocupacional según lo que describe Kronenberg y Pollard (2007) en la escuela Hospitalaria ya que se trata de un contexto social que mantiene regularmente apartados a nińos y nińas al acceso de oportunidades que otros seres humanos pertenecientes a su etapa evolutiva, si tienen: Acceso a desempeñar ocupaciones de manera voluntaria, libre, activa e independiente como las de cualquier otro niño o niña, más allá de su condición de salud física.

Me resultó interesante proponer un paralelo entre esta situación y un hecho histórico que conocí estando en Brasil. Ese país durante el término de la época de esclavitud, vivió una condición similar, donde las personas negras, si bien, ya gozaban de "libertad", bajo acuerdos políticos y firmas de contratos de liberación, su esclavitud socio-política seguía estando vigente ya que se les estaba prohibido el acceso a lugares públicos como iglesias, plazas, teatros, etc., quedando así confiscados en sus casas, sin saber leer ni escribir. Acostumbrados ellos y ellas a vivir y actuar bajo órdenes de un señor que comandaba sus vidas, la modificación legal realizada en lo jurídico, no cambió su condición de esclavos en lo cotidiano, al no re-estructurar una concepción social sobre las ideas de raza que generaban la discriminación civil que los mantenía alejados del mundo público y de una libre y genuina participación comunitaria. Esta situación mantuvo a los y las pobladoras negras impedidas de desarrollar de manera independiente sus propias vidas. Tomando este ejemplo creo que la situación que viven los y las estudiantes de edades que fluctúan entre los 4 y los 12 ańos de edad y que asisten a la escuela hospitalaria hace 3 o 4 años, es decir desde que comenzó sus etapa escolar viven una situación de Apartheid Ocupacional. Si bien la escuela hospitalaria, se preocupa de brindarle educación gratuita durante su periodo de hospitalizaciones, propiciando que sus necesidades educativas sean satisfechas, no se debe olvidar que existen además otras necesidades vitales en su ciclo de vida. Al pertenecer a una comunidad escolar extremadamente cerrada, diferenciada y sobreprotegida, más aún que una escuela especial me comienzo a preguntar ¿hasta qué punto estos cuidados y atención personalizada y clínica se reconoce como necesaria? ¿Cuál es el límite de ese "estigma social" de la "compasión" que recae sobre los niños y niñas que pasan por procesos de patologías diversas en un hospital? ¿Es su condición de "enfermo" o "enferma" permanente de hospital, diferente al de la persona enferma de la vida cotidiana que va por la calle o que está en su casa? (SONTAG, 1980).

Mientras realizo este trabajo percibo que las condiciones políticas de nuestra sociedad son las que estructuran la manera "natural" en que la condición de discapacidad adopta un significado y que condiciona nuestra forma de relacionarnos con ella. Grandes instituciones en Chile, como por ejemplo, las campañas de Teletón, contribuirán, a la elaboración de estas condiciones políticas. 
En esta investigación planteo que son estas condiciones políticas las principales barreras para acceder a la participación ocupacional igualitaria de los nińos y las niñas que poseen condiciones de salud divergentes a las del resto de la población y que serán las propias concepciones sociales con las que yo y todos nosotros nos aproximamos a ellos y ellas, las que generan el Apartheid Ocupacional al que se refiere Kronenberg y Pollard (2007).

Para concluir esta idea sobre las convenciones generadas en torno al niño o nińa con enfermedad discapacitante, no puedo dejar de recorrer brevemente lo propuesto por Sontag (1980) en su libro "La enfermedad y sus Metáforas". La autora revisa cómo, a lo largo del siglo XIX, las metáforas patológicas se hacen más virulentas, descabelladas y demagógicas, desarrollando la tendencia cada vez mayor a usar la palabra "enfermiza" como expresión que denomina cualquier situación con la que no se esté de acuerdo y que por lo tanto se considere "anormal". Se desvirtúa la idea de enfermedad, la cual sabemos existe tan legítimamente natural como existe la idea de salud.

Enfermedad en siglo XIX comienza a ser sinónimo de lo que es "contra-natura". En 1800 Bichat, citado por Sontag (1980) definió la vida como "el conjunto de funciones que resisten a la muerte". Este contraste, entre vida y muerte, se convertiría luego en un contraste entre vida y enfermedad, lo que nos llevaría en este camino interminable hacia la concepción binomia de las formas de habitar la vida. La enfermedad, ahora equivalente a la muerte, es lo que se opone a la vida, siendo luego, durante el siglo XX, la condición de "enfermo de cáncer" la que guarda el núcleo supremo de la metáfora, ya que se trata de una enfermedad tan sobrecargada de mixtificación y tan agobiada por la fantasía de un destino ineluctablemente fatal que hasta dentro del lenguaje político se hace referencia al "cáncer de la humanidad" como aquello que acaba sin piedad la condición humana moralmente correcta que intenta sobrevivir.

Así como las metáforas de la enfermedad que Sontag (1980) analiza, existen también las asociaciones innatas hacia las instituciones hospitalarias ligadas a las ideas de malestar o muerte y que se encuentran incluidas en la retórica de la vida diaria, como parte de un cotidiano irremediable, pero temible y horrorizado, lo que afecta todavía más en la perpetuación de las ideas concebidas en torno a las diversas condiciones de salud que los niños y niñas presentan y por lo tanto influirán en las oportunidades de exploración y desempeño en actividades de juego que ellos y ellas tienen. Por lo tanto, facilitarles ocupaciones depende de las influencias políticas y culturales que existen en su entorno social y económico y sabemos que la posibilidad de que ellos y ellas participen activamente del mundo de los privilegios y oportunidades, no depende sólo de sus propias habilidades, sino también del deseo socio-cultural que se lo permita. Así el poder actúa para controlar los comportamientos microscópicos de cada individuo e influir en ellos y en sus opciones, para que no se planteen presuntas tan amplias como por ejemplo ¿Dónde, porqué y quién toma las decisiones que determinan las opciones limitadas de las cuales disponen los actores que construyen el mundo? Por esto, si bien, a través del desarrollo de esta experiencia sabía que no podría cambiar el mundo, sí busqué remover y dejar resonando los cuestionamientos sobre estos asuntos, teniéndolos presentes a la hora de comprometerme en el trabajo activo-participativo con una grupalidad con dificultades.

\section{E1 teatro en la Escuela}

Para poder entender el teatro dentro del aula tenemos que ordenar el pensamiento en dos niveles, ya que generalmente se le considera sólo como una actividad extra-programática valiosa, que entretiene a los niños y niñas en las escuelas. Así en un primer nivel el teatro debe ser considerado como una disciplina de creación artística, seria y generadora de obras de arte, como las de cualquier artista adulto. En otro nivel el teatro en la escuela será también una herramienta para la formación y el desarrollo personal.

En este caso, para el taller que decidí desarrollar en la escuela Hospitalaria usé este recurso de las técnicas corporales que implican el arte teatral y la posibilidad de libre creación y expresión de ideas, como medio para transformar una jornada en la escuela y así propiciar ocupaciones satisfactorias y elegidas por los niños y las nińas.

La escuela regular en nuestro contexto chileno, responde a la necesidad moral de estructurar un "deber ser" y todavía no ha sido capaz de adaptarse a las reales necesidades de niños y niñas. El teatro es una de las múltiples instancias que facilitarían el desarrollo de escuelas creativas y liberadoras (DÍAZ; GENOVESE, 1993). Esta innovación metodológica es una idea que ya hace muchos años se propone trabajar en Chile, pero que todavía debe esperar por cambios paradigmáticos de nuestro sistema educativo para ser concretada.

En la escuela hospitalaria existe además la potencialidad del uso del teatro desde su dimensión terapéutica, ya que a través de él es posible trabajar 
con y desde las dificultades del campo físico, mental o emocional de los nińos y niñas, para facilitar, por ejemplo su integración social. A través del acto creativo, ellos y ellas reconocen, comprenden y comparten sus habilidades y luego sus limitaciones, reevaluándose y aumentando su autoestima (PACHECO; ZORRILLA; CÉSPEDES, 2007).

Por esto, para el taller que realicé escogí el teatro como herramienta central. Validando el proceso del grupo, el recorrido, como una forma de dejar en claro que lo más importante, cuando hacemos teatro en las escuelas, no es la presentación final de una obra, sino más bien la experiencia y participación de cada estudiante en el descubrimiento de sí mismos y la creación colectiva.

Hay que proseguir el ensayo

No importa que debamos improvisar

Que no haya un director

Y que la pieza que ensayamos no se estrene nunca

También la flor es un ensayo

La palabra es un ensayo

El silencio es un ensayo

Los dioses fueron un ensayo

Aunque el anfiteatro esté vacío

Y nos desnuden las ausencias,

Como a la flor desnuda

El hecho elemental de que todo no sea flor, que el aire no sea flor

Que el tiempo, el pensamiento no sean flor.

Aunque la voz del hombre esté llena de huecos

O tal vez sea un hueco,

Hay que proseguir el ensayo.

Es el único modo

De que al menos los otros ensayos quizás se estrenen algún día.

Y entonces tal vez ellos nos arrastren

(JUARROZ, 1988, p. 139).

\section{$6 \mathrm{El}$ trabajo en el taller- algunos conceptos}

En este apartado quiero analizar algunos conceptos trabajados durante el transcurso del taller que me parecen importantes de considerar a la hora de ejecutar actividades como esta, en grupos. Los conceptos trabajados fueron: "Sentido de Pertenencia" referido a lo que Alfaro (2014) describe como un elemento primario de arraigo e identificación personal que una persona desarrolla hacia un grupo específico y que en este caso todos y todas fuimos adquiriendo con el tiempo. El sentido de pertenencia surgió sólo después de cinco o seis sesiones.

El "vínculo de grupo" es entendido como un lazo de confianza y compromiso entre personas, y en este caso, donde el niño o la niña que participa de una relación con pares y/o adultos, experimenta y/o puede/debe experimentar la autovalía, autoconfianza y autonomía. Para que estas experiencias existan es necesario abrir el camino, permitir este desarrollo, siendo entonces compañeros y compañeras, personas en relaciones horizontales y así acompañarnos en el proceso de adquirir las habilidades necesarias para enfrentarnos a nuestra sociedad (BARUDY, 2005).

"Juego cooperativo" donde priman las actividades simbólicas y creativas que poco a poco se van complejizando hacia actividades artísticas y altamente estructuradas y que establecen la base para el avance posterior hacia un Juego reglado de mayor complejidad. Este tipo de juego, en contraposición al juego competitivo, posee también la importancia de facilitar el desarrollo de habilidades sociales pero sobre todo de valores, estableciendo la percepción que el niño o la niña tienen de sí mismos y de los demás compañeros, como jugadores, sus destrezas y sus posibilidades de logro mientras juegan. Su foco se centra en la invitación a vivenciar la colaboración mutua y el compromiso con el colectivo.

“Creatividad” que para González ([19--]) es un proceso psíquico superior que permite hallar relaciones y soluciones novedosas a las dificultades de la vida diaria, partiendo de informaciones ya conocidas y que abarca no sólo la posibilidad de solucionar problemas, sino también la de plantear nuevos desafíos e interrogantes, logrando reconocer el mundo que nos rodea en sus infinitas posibilidades.

“Expresión corporal", entendemos que expresarse significa declarar, dar a entender o manifestar algo a otros a través de la palabra, pero en este caso buscamos aprender que el cuerpo es un medio fundamental para esas otras modalidades de expresión, que tenemos en la vida. Esto implica la necesidad de que el cuerpo sea dispuesto y preparado de modo de reflejar sentimientos, ideas, pasiones. Todo lo que nos sucede, nos sucede en el cuerpo. No hay evento que afecte nuestras almas que no movilice los cuerpos. Entre los cuerpos hay diálogos permanentes siempre. Entre mi cuerpo y la silla de ruedas, entre tu cuerpo y el cuerpo musical que toco en la guitarra 
(guitarra, silla de ruedas que también son cuerpos), entre mis ojos y tus ojos que también son cuerpo.

"Autoestima" que corresponde a una experiencia íntima personal, generada de la suma de la confianza y el respeto que debemos sentir por nosotros mismos y refleja el juicio de valor que cada uno hace de su persona para enfrentarse a los desafíos que presenta la existencia, siendo la visión más profunda que cada cual estructura de sí mismo en la aceptación o negación de la propia identidad y se sustenta en el concepto de la valía personal y de la capacidad (HORNSTEIN, 2011).

"Resiliencia" la cual se define como aquella capacidad humana para enfrentar, sobreponerse y ser fortalecidos, empoderados o transformados por la adversidad (HENDERSON, 2003). ¿Quién, de los que hoy leen, no ha sobrevivido a sus propias catástrofes? Siempre fuimos resilientes, sucede que este concepto fue creado sólo hace unos pocos años, pero la resiliencia existe en el corazón de todos los seres humanos desde el origen.

Estos conceptos correspondieron a una compleja red de situaciones que fueron descritas en el registro autoetnográfico completo del taller de teatro y que para fines de la investigación fueron analizados de manera simplificadora.

\section{E1 Taller de Teatro: "Locomotora el Teatro me Lleva a la Escuela"}

En el registro ampliado de esta investigación se describió desde las sesiones de Marzo en adelante cómo poco a poco iban aconteciendo sucesos que demostraban la identificación que los niños y niñas desarrollaban con el grupo, dando cuenta de lo que según Alfaro (2014) corresponde a ese "sentido de pertenencia grupal” como expresión concreta de adhesión a rasgos específicos y característicos de la grupalidad. Así, cuando ellos y ellas fueron capaces de darle nombre a su propia banda musical; desempeñar roles específicos como encargado de mantener el orden en el espacio o apoyar las creaciones de los y las compañeras; crear sus propias máscaras para presentar una función para sus madres en el mes de Mayo; jugar en parejas no sólo porque yo se los pedía, sino también porque era parte de la dinámica del grupo encontrarse con un compañero o una compañera frente a frente para crear; saber que siempre "estar ahí" significaba juego y soltura, era nuestro "espacio especial/espacial de hacer teatro”. Como lo propone Alfaro (2014), existía una decisión de adherir a este grupo como fruto de una participación protagónica en los procesos de creación y construcción de contenidos, lo cual determinó este Sentido de Pertenencia consciente y activo.

Se logró, a través de las múltiples actividades, que todos nos re-conociéramos, con identidad propia, más allá de las diferencias físicas evidentes (como elementos perceptibles), reconocernos como personas únicas y, al mismo tiempo, capaces de ser reconocidos por lo demás. La identidad colectiva se construía a partir de las semejanzas y diferencias que mantenían cohesionado al grupo. Considerando que ellos y ellas son nińos y nińas, y que su etapa evolutiva corresponde al comienzo del desarrollo de lo que en el futuro será su identidad, como grupo construíamos en nuestras interacciones ideas colectivas, de múltiples significados que nos afectaban y movilizaban internamente.

La noción de "Vinculo grupal", como concepto que profundiza en los lazos afectivos que indirectamente se desarrollaron en nuestro taller, fue de especial relevancia. En este caso vínculos afectivos que buscaban no solo la sana y buena convivencia (BARUDY, 2005), sino que fueran relaciones interpersonales que permitieran a cada uno la auto-validación en el manejo y conocimiento de las propias habilidades, confiando, por ejemplo, en saber cuál era el rol que nos tocaba ejercer, cuáles son nuestros aportes, cuáles eran las probabilidades de error y triunfo en las actividades desarrolladas. Sentir que este - estar juntos - más allá de nuestra condición de niño, niña o adulta, todos teníamos la autonomía, para decir y decidir lo que quiero y no quiero hacer.

Entre los aspectos teóricos sobre el juego cooperativo de Romero y Garvín (2003), la "Expresión corporal" y la "Creatividad" (GONZÁLEZ, [19--]) existen vinculaciones inseparables una de la otra, por este motivo les analizo de manera transversal. El juego grupal entrega retroalimentación a cada jugador y jugadora sobre sus capacidades, y estimula y propicia instancias para la expresión corporal, donde siempre habrá movimiento, más allá de las discapacidades físicas, y donde "quietud" no quiere decir inmovilidad. Nuestros cuerpos se mueven, ya lo dijimos anteriormente.

El cuerpo quieto mueve los ojos, respira suave y a través de eso, expresa. Por tanto la expresión corporal está presente en el juego de todos los niños y las niñas, donde la motivación por divertirse será la principal sensación movilizadora. Además es muy importante destacar el avance que niños y niñas tuvieron en el ejercicio de expresarse utilizando sus cuerpos de maneras diferentes y creativas, permitiéndoles reconfigurar sus modos de comunicación. Ahora decían hambre moviendo los brazos sobre su 
estómago, decían risa levantando las manos, decían pena mirando fijamente a los ojos.

A través de estas nuevas formas de expresión podemos vivenciar la creatividad. Esa creatividad que González ([19--]) llama proceso psíquico superior, en la infancia se encuentra inalterada por los "bloqueos sociales", que luego como adultos adquirimos, como lo señala Papalia, Wendkos y Duskin (2009) y González [19--]) Jugar a las esculturas, a narrar historias y/o imágenes con nuestros cuerpos, nos permitió descubrir que cuando nos liberamos del "juicio" que los bloqueos sociales nos imponen, la expresión es más fluida y fácil.

Como resultado de estas dinámicas teatrales desde el primer y hasta el último día, pudimos asistir a ese "entre", a ese encuentro entre cuerpos, a ese proceso vivencial más importante que la función de una obra final. Viví el fortalecimiento grupal paulatino de la autoconfianza que señala Pacheco, Zorrilla y Céspedes (2007). Se generó un sentimiento personal de creer con confianza que los desafíos propuestos, eran posibles de realizar. A partir de pequeñas creaciones colectivas, que servían de ensayos, se fue generando una presentación final que luego las familias y seres queridos aplaudieron con lágrimas en los ojos. Sin dudas esta experiencia nos generó una sensación de validación, respeto y consideración hacia nosotros mismos con nuestras dificultades y propios obstáculos. Papalia, Wendkos y Duskin (2009) dirá que la Autoestima corresponde al punto de vista del "yo" capaz de alcanzar las tareas que se propone en la vida y además poder compartir éstos logros con otras personas nos ayudará a sentirnos satisfechos con nuestro desempeño y esa satisfacción será el sentimiento de auto-valía que todos necesitamos para crecer. Si bien, durante el taller, siempre fue importante y central la participación de los niños y las niñas, es necesario destacar cómo se fortalecieron estos aspectos socioemocionales trabajando poco a poco en alcanzar pequeños objetivos. Dijimos que presentar un espectáculo final como único objetivo de un Taller de Teatro en la escuela era el error más recurrente cometido, por esto resalto la importancia que tuvo para todos nosotros vivir el proceso lentamente y que a partir de las creaciones colectivas generadas en los encuentros semanales se gestara una obra final con vida propia. Ella nació sola, de los encuentros de nuestros corazones y cuerpos jugando.

Era muy importante para mí, como monitora de este taller, que todos estos conceptos fueran desarrollados, dado que funcionan como factores protectores y promotores, según Papalia, Wendkos y Duskin (2009), del desarrollo de la resiliencia en los niños y niñas. Las autoras mencionan que una de las aristas que conforman la resiliencia corresponde a la capacidad cognitiva del nińo o la niña de percibir o vivenciar los hechos de maneras variadas, teniendo la flexibilidad de pensamiento suficiente como para encontrar diferentes causas y variadas soluciones para una experiencia adversa, encontrándose estrechamente vinculado a la capacidad que la persona tiene de expresar lo que piensa y siente a través de la expresión corporal y oral, y así reconocerse a sí mismo como uno de los múltiples factores que componen la complejidad de las situaciones de la vida. Es necesario afrontar las dificultades de forma más ligera y sin creatividad, según González ([19--]), no se romperán jamás con esas formas de habitar el mundo, de modo tal que las estructuras de poder y las condiciones determinantes de la vida quedarán inalterables.

Lo anterior como análisis de esta investigación suena bastante alegórico, sin embargo, es el resultado de mis visiones, sensaciones y escucha. Es detallado, porque durante el taller de teatro vivimos constantemente circunstancias donde nuestros espíritus resilientes, salieron a la luz. Quiero destacar dos momentos claves donde esto se manifestó de manera más importante. El primero fue en el mes de Julio, cuando uno de los niños en tratamiento de quimioterapia, recién llegado a la escuela estaba asustado y desconfiado esperando que llegara la hora de su atención médica. Sus padres señalaron que durante este periodo de tratamiento lo dejaban en casa para que estuviera más resguardado de las posibles infecciones a las que se podría ver expuesto y que evitaban que asistiera a la escuela hospitalaria continuamente. Ese día el nuevo integrante en pocos minutos ya estaba riendo al verse en el espejo con su cara pintada por el maquillaje. Su risa abrió las puertas para que se generara rápidamente una interacción y el movimiento grupal surgió solo. Nos olvidamos que unos minutos más tarde venia la intervención médica que últimamente lo dejaba sin energías en su casa.

La segunda experiencia que quedó registrada fue el esfuerzo que el personaje de nuestra obra final, el '"payaso malvado" realizó viajando desde una ciudad a otra, sólo para cumplir con su personaje y estar presente en la función final. Este participante tiene Parálisis cerebral y usa silla de ruedas. Pocos días antes de la presentación se fracturó una pierna, lo que lo tenía con mayores dificultades para trasladarse hasta la escuela y por esto no estaba asistiendo. Él vive en un pueblo a 45 minutos de nuestra ciudad. Por esto, decidí que era importante ir hasta su casa y pedirle que no abandonara su papel en la obra. Le dije que lo necesitábamos. Su familia valoró mucho esta 
petición y así sobreponiéndose a las dificultades que lo impedían, se esforzaron por llegar el día final del taller. El "Payaso malvado" estuvo en la obra y su felicidad nos desbordó.

Finalmente es posible evaluar que si bien, no existieron parámetros de medición cuantitativos y objetivos que especificaran el logro o el no logro del desarrollo de los conceptos propuestos en esta investigación, es mediante la utilización de esta descripción subjetiva, que la metodología autoetnográfica me permite, que es posible dar cuenta de cómo los conceptos descritos aquí se vieron evidenciados como herramientas útiles no sólo en el combate de las circunstancias opresivas del desempeño escolar de estudiantes de una escuela hospitalaria, sino que también en el desarrollo en mi como monitora del taller. Las circunstancias descritas al comienzo de este documento se encontraban de manera general siendo avaladas y normalizadas por todos nosotros en el cotidiano. Fue gracias a este ejercicio reflexivo - investigativo que pude darme cuenta de ellas, evaluarlas y así usarlas estratégicamente a nuestro favor en la transformación de un contexto específico y en mi propia vida.

\section{Conclusion}

Para poder realizar el análisis final "concluyente" es necesario aclarar que a través de éste, no se pretende finalmente "concluir", sino que más bien se busca invitar a desprender de él sugerencias e ideas claves conducentes a nuevas interrogantes y tal vez nuevos y mejores caminos de investigación. Teniendo presente que lo aquí fue descrito corresponde a una mirada focal de un lugar específico y no busca generalizar ni reducir los procesos narrados a mi mirada singular como investigadora.

$\mathrm{Si}$ bien en el relato existieron muchos detalles que quedaron fuera del alcance de la narración, se desprenden de él, situaciones que dejaron en evidencia las diversas circunstancias que estructuraban aquellos "Factores de Riesgo Ocupacional" en el desempeño de los niños y las niñas. Desde las formas de relacionarse que profesoras y personal administrativo de la escuela hospitalaria establecen con ellos y ellas, hasta los espacios físicos donde su rutina escolar era realizada.

Es importante recalcar que es necesario permanecer atentos a las múltiples condiciones que en algunas ocasiones nos llevan a no percibir que podrían existir elementos en el entorno que están impidiendo el desempeńo Ocupacional de quienes lo habitamos, condicionando situaciones de Desequilibrio y Deprivación Ocupacional, al impedir la elección y/o el desempeño voluntario de nuestras ocupaciones vitales. Espacios físicos reducidos o no aptos para el tránsito de personas con características diferentes, estructuras curriculares en las escuelas que otorgan escasa variabilidad de actividades o disminuida presencia de aprendizaje de las diversas artes, son algunas de las condiciones que probablemente no son frecuentemente valoradas como elementos de riesgo para un adecuado desarrollo en niñas y niños y para el establecimiento de su bienestar. Situaciones "normalizadas" dentro de los contextos escolares que van entorpeciendo las posibilidades personales de un ser humano. Frente a estas situaciones la desestructuración que significa proponer dinámicas teatrales y/o artísticas dentro de las estrategias pedagógicas resulta efectivamente ser una medida de rebeldía a la rutina. La pregunta a estas alturas es ¿Qué tan efectivas son instancias como estas donde luego de que el taller se termina, toda la vida sigue igual? Aquí el "vínculo grupal” y el "sentido de pertenencia" generados, cobran mayor importancia, ya que así algo más que sólo el recuerdo quedará en todos nosotros. Ese lugar único llamado grupo, donde nos sentimos identificados y que nos proporcionará herramientas personales a las cuales acudir en defensa de nuestro propio bienestar estarán siempre ahí para el futuro. Así resulta combativo el uso del arte en la desestructuración de condiciones opresivas y de "Apartheid Ocupacional" normalizadas por la sociedad.

Finalmente es necesario no dejar de criticarme a mí misma en las decisiones que tomé, en cada acción y/o frase depositada en este texto, ya que para el futuro el teatro seguirá siendo mi herramienta de lucha y lo que intento proponer es que el arte, así como me salvó la vida a mí, posee el potencial en este caso, de sembrar inquietudes artísticas, de expresión y creatividad también en los demás y por lo tanto necesitaré permanecer en este estado de alerta frente a las continuas situaciones opresivas que mi propio lenguaje puede generar en mis encuentros con los otros. Como individua e integrante de grupalidades de personas que trabajan con personas, creo fuertemente en que es necesario como herramienta de lucha contra los Factores de Riesgo y las condiciones de Apartheid Ocupacional que nos abordan y atraviesan a todos, que siempre propiciemos, en nuestros diferentes contextos, espacios de "no evaluación" y libertad para el uso, disfrute y despliegue de todas nuestras características personales, de tal manera de reconocerlas, trabajarlas, evaluarlas y reflexionar sobre ellas. Es imprescindible tener la certeza de que aunque luego "la vida siga igual", el 
cuerpo guarda las vivencias y a partir de eso cree, nace y renace, reviviendo lo vivido, cada vez que pueda. Este hecho sin lugar a dudas potenciará esa alma resiliente que todos y todas merecemos tener y abrirá el camino a la posibilidad de destruir nuestras condiciones determinantes, a todo eso que nos dicen "debemos ser".

\section{Referencias}

ALFARO, A. T. V. Identidad y sentido de pertenencia: una mirada desde la cotidianeidad. La Habana: Centro Prov. de Cultura Comunitaria, 2014. Disponible: <http://132.248.35.1/cultura/ponencias/1cultDesa/ CDIDE02.htm>. Acceso: 19 feb. 2014.

BARUDY, J. Los buenos tratos a la infancia: parentalidad, apego y resiliencia. Barcelona: Gedisa, 2005.

CHILE. Ministerio de Educación. Línea de innovación escuelas y aulas hospitalarias. Santiago, 2015. Disponible: <http://www.mineduc.cl/index2.php?id_ portal $=20 \&$ id_seccion $=3007 \&$ id_contenido $=11814>$. Acceso: 22 mayo 2015.

CHILE. Ministerio de Planificación. Ley 20.422, de 21 de enero de 2010. Establece normas sobre igualdad de oportunidades e inclusión social de personas con discapacidad, Diario Oficial, Santiago, 21 enero 2010. Disponible: <http://www.leychile.cl/ Navegar?idNorma=1010903 >. Acceso: 22 mayo 2015.

DÍAZ, J.; GENOVESE, C. Manual de teatro escolar. Santiago: Salesiana, 1993.

ESTEBAN, M. L. Antropología encarnada: antropología desde una misma. Papeles del CEIC, País Vasco, n. 12, p. 1-21, 2004

FERLAND, F. O modelo lúdico: o brincar, a criança com deficiência física e a terapia ocupacional. São Paulo: Roca, 2006.

FERNÁNDEZ, R. Memoria y Conmemoración del golpe de estado de 1973 en Chile: la marcha del 11 de septiembre desde una perspectiva autoetnográfica. 2006. $108 \mathrm{f}$. Tesis (Magíster en Psicología Social) - Universidad de Barcelona, Barcelona. 2006.

GONZÁlEZ, X. Apuntes de creatividad. Santiago: Ediciones Universidad de Chile, [19--].
HENDERSON, E. Nuevas tendencias en resiliencia, descubriendo las propias fortalezas. 2003. Disponible: <http://www.addima.org/Documentos/Nuevas\%20tendencias\%20en\%20resiliencia\%20Grotberg.pdf>. Acceso: 22 mayo 2015.

HOLMAN, J. S. Autoethnography: making the personal political. In: DENZIN, N.; LINCOLN, Y. The sage handbook of qualitative research. California: Sage, 2005. p. 763-791.

HORNSTEIN, L. Autoestima e identidad: narcisismo y valores sociales. Buenos Aires: Fondo de Cultura Económica, 2011.

JUARROZ, R. Undécima poesía vertical. Buenos Aires: Ediciones C, 1988.

KRONENBERG, F.; POLLARD, N. Superar el Apartheid Ocupacional Exploración preliminar de la naturaleza política de la Terapia Ocupacional. In: KRONENBERG, F.; POLLARD, N.; SIMÓ, S. Terapia Ocupacional Sin Fronteras: aprendiendo del espíritu de supervivientes. Madrid: Médica Panamericana, 2007. p. 58- 83.

LUCERO, F.; TRIVIÑOS, M. Desarrollo del juego en niños y niñas pertenecientes a las Residencias para Mayores Padre Hurtado y Renace de la ciudad de Valdivia. 2010. 79 f. Tesis (Grado de Licenciado en Ciencias de la Ocupación) - Universidad Austral de Chile, Chile, 2010.

MÉNDEZ, X. et al. Atención psicológica en el cáncer infantil. Revista Electrónica de Psicooncología, Madrid, v. 1, n. 1, p. 139-154, 2004.

PACHECO, J.; ZORRILlA, M.; CÉSPEDES, P. Plan de orientación y acción tutorial para la educación primaria. Andalucía: Consejería de Educación, 2007. Disponible: <http://www.juntadeandalucia.es/averroes/centrostic/23005499/helvia/sitio/upload/POAT.pdf>. Acceso: 03 marzo 2014.

PAPALIA, D.; WENDKOS, S. Y.; DUSKIN, R. Psicología del desarrollo: de la infancia a la adolescencia. México: McGraw-Hill, 2009.

ROMERO, D.; GARVIN, M. Terapia Ocupacional: teoría y técnicas. Barcelona: Masson, 2003.

SONTAG, S. La Enfermedad y sus metáforas. Buenos Aires: Taurus, 1980.

WILCOCK, A. An occupational perspective of health. Thorofare: Slack Publishing, 1998.

\section{Contribución de los Autores}

Miriam Maribel Vargas Rivas es la autora de este artículo y la encargada de la ejecución del taller que le dio origen. Es la responsable de la concepción y redacción del texto, además de la organización de las fuentes y el análisis. Daniela Olivares Aising, es profesora orientadora del seminario de Título que dio origen a este artículo. Es encargada de la revisión y asesoría teórica de la investigación y de las reflexiones registradas. Roberto Fernández Droguett es profesor orientador del seminario de Título que dio origen a este artículo. Es encargado de la revisión y asesoría metodológica de la investigación. Todos los autores aproaban la version final del texto. 


\section{Fuente de financiamiento}

Proyecto financiado por Fondo para el Desarrollo de la Cultura y las Artes (FONDART, 2011) del Consejo Regional de la Cultura y las Artes, Región de Los Ríos, Valdivia, Chile.

\section{Notas}

${ }^{1}$ Fondo de Desarrollo de la Cultura y las Artes 2010, para una región de la zona sur de Chile.

${ }^{2}$ Entre estos procesos se destacan principalmente en los niños y niñas con diagnóstico oncológico, la exposición a procedimientos potencialmente estresantes y dolorosos (radioterapia o quimioterapia) los cuales poseen un carácter invasivo que cambia su aspecto físico, lo que puede amenazar su autoestima y comprometer el componente socio-afectivo (dificultades en las relaciones sociales) (MÉNDEZ et al., 2004).

${ }^{3}$ Ley de educación especial que surge de a partir de Ley de integración social ley 20.422, párrafo 2 artículo n ${ }^{\circ} 40$ : Establece que todo alumno o alumna que "[...] padezca de patologías o condiciones médico-funcionales que requieran permanecer internados en centros especializados o en el lugar que el médico tratante determine, o que estén en tratamiento médico ambulatorio, el Ministerio de Educación asegurará la correspondiente atención escolar en el lugar que, por prescripción médica, deban permanecer [...]" (CHIILE, 2010, p. 12)

${ }^{4}$ Gracias a este tipo de iniciativas se ha logrado, a partir del año 1999 y hasta la fecha, crear 29 escuelas y aulas hospitalarias en el país, atendiendo una matrícula mensual de entre 1000 y 1.200 estudiantes. (CHILE, 2015).

${ }^{5}$ Este aspecto se encuentra también condicionado por las repetidas fases de inmunosupresión que las personas experimentan a lo largo de su enfermedad, hecho que los vuelve vulnerables y por lo tanto les impide la vinculación social "normal" (MÉNDEZ et al., 2004).

${ }^{6}$ Ferland (2006) resalta que la Terapia Ocupacional percibe el juego como la modalidad privilegiada de intervención y como la Ocupación central de la vida de un niño. 